\title{
Markers of systemic inflammation in response to osmotic stimulus in healthy volunteers
}

\author{
Clara Odilia Sailer ${ }^{1,2}$, Sophia Julia Wiedemann ${ }^{1,3}$, Konrad Strauss $^{4}$, Ingeborg Schnyder ${ }^{1}$, Wiebke Kristin Fenske ${ }^{5,6}$ and \\ Mirjam Christ-Crain ${ }^{1,2}$
}

${ }^{1}$ Department of Endocrinology, Diabetology and Metabolism, University Hospital Basel, Basel, Switzerland

${ }^{2}$ Department of Clinical Research, University of Basel, Basel, Switzerland

${ }^{3}$ Department of Biomedicine, University of Basel, Basel, Switzerland

${ }^{4}$ Division of Endocrinology and Diabetes, Department of Internal Medicine I, University Hospital, University of Würzburg, Würzburg, Germany

${ }^{5}$ Leipzig University Medical Center, Integrated Center for Research and Treatment Adiposity Diseases, Leipzig, Germany

${ }^{6}$ Medical Department III, Endocrinology, Nephrology, Rheumatology, University Hospital of Leipzig, Leipzig, Germany

Correspondence should be addressed to C O Sailer: clara.sailer@usb.ch

\begin{abstract}
Osmotic stimulus or stress results in vasopressin release. Animal and human in vitro studies have shown that inflammatory parameters, such as interleukin-8 (IL-8) and tumor necrosis factor- $\alpha$ (TNF- $\alpha$ ), increase in parallel in the central nervous system and bronchial, corneal or intestinal epithelial cell lines in response to osmotic stimulus. Whether osmotic stimulus directly causes a systemic inflammatory response in humans is unknown. We therefore investigated the influence of osmotic stimulus on circulatory markers of systemic inflammation in healthy volunteers. In this prospective cohort study, 44 healthy volunteers underwent a standardized test protocol with an osmotic stimulus leading into the hyperosmotic/hypernatremic range (serum sodium $\geq 150 \mathrm{mmol} / \mathrm{L}$ ) by hypertonic saline infusion. Copeptin - a marker indicating vasopressin activity - serum sodium and osmolality, plasma IL-8 and TNF- $\alpha$ were measured at baseline and directly after osmotic stimulus. Median (range) serum sodium increased from $141 \mathrm{mmol} / \mathrm{L}(136,147)$ to $151 \mathrm{mmol} / \mathrm{L}(145,154)(P<0.01)$, serum osmolality increased from $295 \mathrm{mmol} / \mathrm{L}$ $(281,306)$ to $315 \mathrm{mmol} / \mathrm{L}(304,325)(P<0.01)$. Median (range) copeptin increased from $4.3 \mathrm{pg} / \mathrm{L}(1.1,21.4)$ to $28.8 \mathrm{pg} / \mathrm{L}(19.9,43.4)(P<0.01)$. Median (range) IL-8 levels showed a trend to decrease from $0.79 \mathrm{pg} / \mathrm{mL}(0.37,1.6)$ to $0.7 \mathrm{pg} / \mathrm{mL}(0.4,1.9)(P<0.09)$ and TNF- $\alpha$ levels decreased from $0.53 \mathrm{pg} / \mathrm{mL}(0.11,1.1)$ to $0.45 \mathrm{pg} / \mathrm{mL}(0.12,0.97)(P<0.036)$. Contrary to data obtained in vitro, circulating proinflammatory cytokines tend to or decrease in human plasma after osmotic stimulus. In this study, osmotic stimulus does not increase circulating markers of systemic inflammation.
\end{abstract}

\author{
Key Words \\ - TNF- $\alpha$ \\ - interleukin-8 \\ - interleukin-6 \\ copeptin \\ - hyperosmolality
}

\section{Introduction}

Hypernatremia and hyperosmolality are common among hospitalized patients and especially among those in the intensive care unit (up to 9\%) and are associated with substantial morbidity and mortality (1). Causes of hypernatremia and hyperosmolality range from dehydration due to volume loss (e.g., diarrhea, sweating) or diabetes insipidus, to salt overload (2).
Hypernatremia and hyperosmolality induce shrinking of cells, mainly in the central nervous system, leading to neurological dysfunctions and symptoms such as thirst, disorientation, lethargy, convulsion and ultimately death (3). Hypernatremia and a consequent rise in serum osmolality increase the perception of thirst and induce the secretion of the hormone arginine vasopressin (AVP) https://ec.bioscientifica.com https://doi.org/10.1530/EC-19-0280 (c) 2018 The authors Published by Bioscientifica Ltd
Endocrine Connections (2019) 8, 1282-1287 
leading to a reduced renal water excretion $(3,4)$. Animal data have shown that upon hypernatremia and hyperosmolality, together with AVP secretion, there is an upregulation of inflammatory markers in the supraoptic and paraventricular nuclei of the hypothalamus $(5,6)$. Furthermore, it was shown that hyperosmolality increases the secretion of proinflammatory cytokines from macrophages (7). Human in vitro studies in bronchial, corneal and intestinal cell lines consistently showed an increased inflammatory response with an increase in interleukin-6 (IL-6), interleukin-8 (IL-8) and tumor necrosis factor alpha (TNF- $\alpha)$ upon hypernatremia and hyperosmolality $(8,9,10,11,12,13)$. Human in vivo studies investigating the effect of hypernatremia on the inflammatory system are scarce. In patients with systemic inflammatory response syndrome (SIRS) due to ketoacidosis and hyperosmolality, an increase in inflammatory parameters was observed, but no other data are available (14).

To the best of our knowledge, no study has looked at the isolated effect of hypernatremia and hyperosmolality on systemic inflammatory markers in healthy volunteers. The aim of this study was therefore to prospectively investigate circulating markers of systemic inflammation in healthy volunteers undergoing a hypertonic saline infusion test in a prospective study.

\section{Materials and methods}

\section{Study design}

This is a secondary analysis of a prospective study including 44 healthy volunteers with available plasma samples (15). Inclusion criteria were normonatremia (serum sodium levels of $135-145 \mathrm{mmol} / \mathrm{L}$ ) and age $>18$ years. Exclusion criteria included a history or presence of polyuria/polydipsia syndrome (24 urinary volume output $>50 \mathrm{ml} / \mathrm{kg}$ body weight), heart failure, liver cirrhosis, nephrotic syndrome or renal failure, anemia, uncontrolled hypertension, chronic alcohol consumption, body mass index $(\mathrm{BMI})<18 \mathrm{~kg} / \mathrm{m}^{2}$ or $>28 \mathrm{~kg} / \mathrm{m}^{2}$, drug intake (except oral contraception), and other therapy-requiring diseases. The study was approved by the Ethical Committee Northwest and Central Switzerland, University of Basel, Basel, Switzerland and the Ethical Committee of the University of Würzburg, Würzburg, Germany. Written informed consent has been obtained from each participant after full explanation of the purpose and nature of all procedures used. The study was registered on ClinicalTrials.gov (NCT02647736).

\section{Study procedure}

The study procedure has been described in detail elsewhere (15). In brief, smoking and alcoholic beverages were allowed until $24 \mathrm{~h}$ before, eating until midnight before and drinking until 06:00h of the test day. On the test day, participants underwent a standardized medical examination and a baseline blood sample for laboratory evaluation of serum sodium, osmolality, copeptin, IL-6, IL- 8 and TNF- $\alpha$ was taken following a 30-min rest in a supine position.

Participants received a $250 \mathrm{~mL}$ intravenous bolus of hypertonic saline ( $3 \%$ saline, $513 \mathrm{mosmol} / \mathrm{L}$ ) within $15 \mathrm{~min}$, which was continued thereafter at a rate of $0.15 \mathrm{~mL} / \mathrm{kg}$ body weight $/ \mathrm{min}$ until serum sodium reached $150 \mathrm{mmol} / \mathrm{L}$ or total infusion time exceeded $180 \mathrm{~min}$. At this time point, a stimulated blood sample was taken for laboratory evaluation of serum sodium, osmolality, copeptin, IL-6, IL-8 and TNF- $\alpha$.

\section{Laboratory measurements}

Laboratory measurements for serum sodium and osmolality were performed immediately in non-frozen samples by automated biochemical analyses. Blood for copeptin, IL-6, IL- 8 and TNF- $\alpha$ analysis was sampled in EDTA tubes, immediately centrifuged at $4^{\circ} \mathrm{C}$, and plasma was stored at $-80^{\circ} \mathrm{C}$ until analysis. Copeptin was measured in a single-blinded batch by a chemiluminescence sandwich immunoassay (B.R.A.H.M.S CT proAVP LIA; Thermo Scientific Biomarkers) as previously described (15). IL- 8 and TNF- $\alpha$ were measured by MSD Mesoscale (V-PLEX Human Proinflammatory Panel II (4-Plex)) according to the manufacturer's specifications. IL-6 was measured in a subset of samples by MSD Mesoscale (V-PLEX Human IL-6 Kit) according to the manufacturer's specifications.

\section{Statistical analysis}

Discrete variables are expressed as absolute numbers, continuous variables as median, interquartile range (IQR 25th, 75th percentiles) and range (min, max). Comparison between baseline and stimulated laboratory values was computed using a Wilcoxon rank-sum test. To adjust for age and sex, a multiple linear regression model and a linear mixed effect model was performed. Graphical analysis was done using boxplots of baseline and stimulated laboratory values, points representing each individual patient. 
Table 1 Baseline characteristics.

\begin{tabular}{|c|c|}
\hline & Healthy volunteers $(n=44)$ \\
\hline Age (years), median (IQR) & $30.0(26,42)$ \\
\hline Weight (kg), median (IQR) & $70(60,80)$ \\
\hline Height (cm), median (IQR) & $174(166,182)$ \\
\hline BMI (kg/m²), median (IQR) & $22.6(21.2,24.9)$ \\
\hline Sex (female), $n$ & 23 \\
\hline $\begin{array}{l}\text { Systolic blood pressure (mmHg), } \\
\text { median (IQR) }\end{array}$ & $122(116,128)$ \\
\hline $\begin{array}{l}\text { Diastolic blood pressure } \\
(\mathrm{mmHg}), \text { median (IQR) }\end{array}$ & $77(70,82)$ \\
\hline Heat rate (1/min), median (IQR) & $63(58,73)$ \\
\hline
\end{tabular}

Data are presented as absolute number ( $n$ ) and median (IQR: 25th, 75th). $\mathrm{BMI}$, body mass index; IQR, interquartile range; $n$, number.

A two-sided $P$ value of $<0.05$ was considered to be statistically significant. Analyses were performed using R statistical software (https://www.r-project.org/).

\section{Results}

\section{Baseline characteristics}

Forty-four healthy volunteers (23 females, 21 males, aged 30 years (IQR 26, 42)) were included in this analysis. Baseline characteristics are shown in Table 1. At the start of the test, serum sodium and osmolality were in the normal range in all participants (Table 2). In a subset of 13 healthy volunteers, we also measured IL-6 ( 6 females, 7 males, aged 30 years (IQR 27,44)) (data not shown).

\section{Sodium, osmolality and copeptin levels upon osmotic stimulus}

After osmotic stimulus, serum sodium increased significantly from $141 \mathrm{mmol} / \mathrm{L}$ (IQR 140, 142; range $136,147)$ to $151 \mathrm{mmol} / \mathrm{L}$ (IQR 150,153 ; range 145,154$)$ $(P<0.01)$ and serum osmolality increased significantly from $295 \mathrm{mmol} / \mathrm{kg}$ (IQR 291, 298; range 281, 306) to $315 \mathrm{mmol} / \mathrm{L}$ (IQR 312, 317; range 304, 325) $(P<0.001)$.
Copeptin increased significantly from $4.3 \mathrm{pg} / \mathrm{L}$ (IQR 3.3, 6.7; range $1.1,21.4$ ) to $28.8 \mathrm{pg} / \mathrm{L}$ (IQR 19.9, 43.4; range 3, 125.2) $(P<0.001)$ (Fig. 1 and Table 2$)$.

\section{Circulatory markers of systemic inflammation upon osmotic stimulus}

After osmotic stimulus, IL-8 tended to decrease from $0.79 \mathrm{pg} / \mathrm{L}$ (IQR 0.65, 1.11; range $0.37,1.6)$ to $0.7 \mathrm{pg} / \mathrm{L}$ (IQR $0.57,0.9$; range $0.4,1.9)(P=0.09)$ and TNF- $\alpha$ decreased significantly from $0.53 \mathrm{pg} / \mathrm{L}$ (IQR 0.39, 0.69; range $0.11,1.1$ ) to $0.45 \mathrm{pg} / \mathrm{L}$ (IQR $0.3,0.53$; range $0.12,0.97$ ) $(P=0.036)$ (Figs 2, 3 and Table 2$)$. In a subset of patients, IL-6 remained unchanged $(0.59 \mathrm{pg} / \mathrm{L}$ before osmotic stimulus, $0.67 \mathrm{pg} / \mathrm{L}$ after osmotic stimulus, $P=0.6$ ) (data not shown).

In a multiple linear regression model adjusting for age and sex, TNF- $\alpha$ remained statistically significant, whereas IL-8 and IL-6 remained statistically non-significant. In a mixed effect model with timepoint (before and after stimulus), age and sex as fixed effects and patients as random effect, TNF- $\alpha$ remained statistically significant, whereas IL-8 and IL-6 remained statistically nonsignificant (Table 3).

Correlation of IL-8 and serum sodium was $R=-0.04$, of IL- 8 and serum osmolality was $R=-0.12$ and of IL- 8 and copeptin was $R=-0.15$. Correlation of TNF- $\alpha$ and serum sodium was $R=-0.14$, of TNF- $\alpha$ and serum osmolality was $R=-0.15$ and of TNF- $\alpha$ and copeptin was $R=-0.1$. Correlation of IL- 6 and serum sodium was $R=-0.13$, of IL- 6 and serum osmolality was $R=0.1$ and of IL- 6 and copeptin was $R=0.1$.

\section{Discussion}

The main finding of this study is that hypertonic saline infusion leading to hypernatremia and hyperosmolality does not lead to an increase in circulating markers of

Table 2 Laboratory values before and after osmotic stimulus.

Laboratory values
Sodium (mmol/L), median (IQR; range)
Osmolality (mmol/kg), median (IQR; range)
Copeptin (pg/L), median (IQR; range)
IL-8 (pg/mL), median (IQR; range)
TNF- $\alpha$ (pg/mL), median (IQR; range)

\begin{tabular}{cc}
\hline & Heal \\
\hline Before stimulus \\
\hline $141(140,142 ; 136,147)$ \\
$295(291,298 ; 281,306)$ \\
$4.3(3.3,6.7 ; 1.1,21.4)$ \\
$0.79(0.65,1.11 ; 0.37,1.6)$ \\
$0.53(0.39,0.69 ; 0.11,1.1)$ \\
\hline
\end{tabular}

Healthy volunteers $(n=44)$

\begin{tabular}{ccc} 
After stimulus & & $P$ value \\
\cline { 1 - 1 } $151(150,153 ; 145,154)$ & & $<\mathbf{0 . 0 0 0 1}$ \\
$315(312,317 ; 304,325)$ & & $<\mathbf{0 . 0 0 0 1}$ \\
$28.8(19.9,43.4 ; 19.9,43.4)$ & & $<\mathbf{0 . 0 0 0 1}$ \\
$0.7(0.57,0.9 ; 0.4,1.9)$ & & 0.09 \\
$0.45(0.3,0.53 ; 0.12,0.97)$ & & $\mathbf{0 . 0 3 6}$ \\
\hline
\end{tabular}

Data are presented as median (IQR: 25th, 75th; range: min, max). Two group comparisons were made using the Wilcoxon rank-sum test. Bold $P$ values represent statistically significant results.

IL-8, interleukin-8; IQR, interquartile range; $n$, number; TNF- $\alpha$, tumor necrosis factor- $\alpha$.

https://ec.bioscientifica.com https://doi.org/10.1530/EC-19-0280 (c) 2019 The authors Published by Bioscientifica Ltd

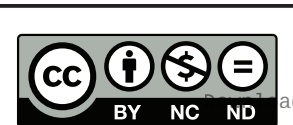

This work is licensed under a Creative Commons Attribution-NonCommercial-NoDerivatives 4.0 Internationab bicense.ifica com at 04/26/2023 $09: 56: 32 \mathrm{Am}$ 

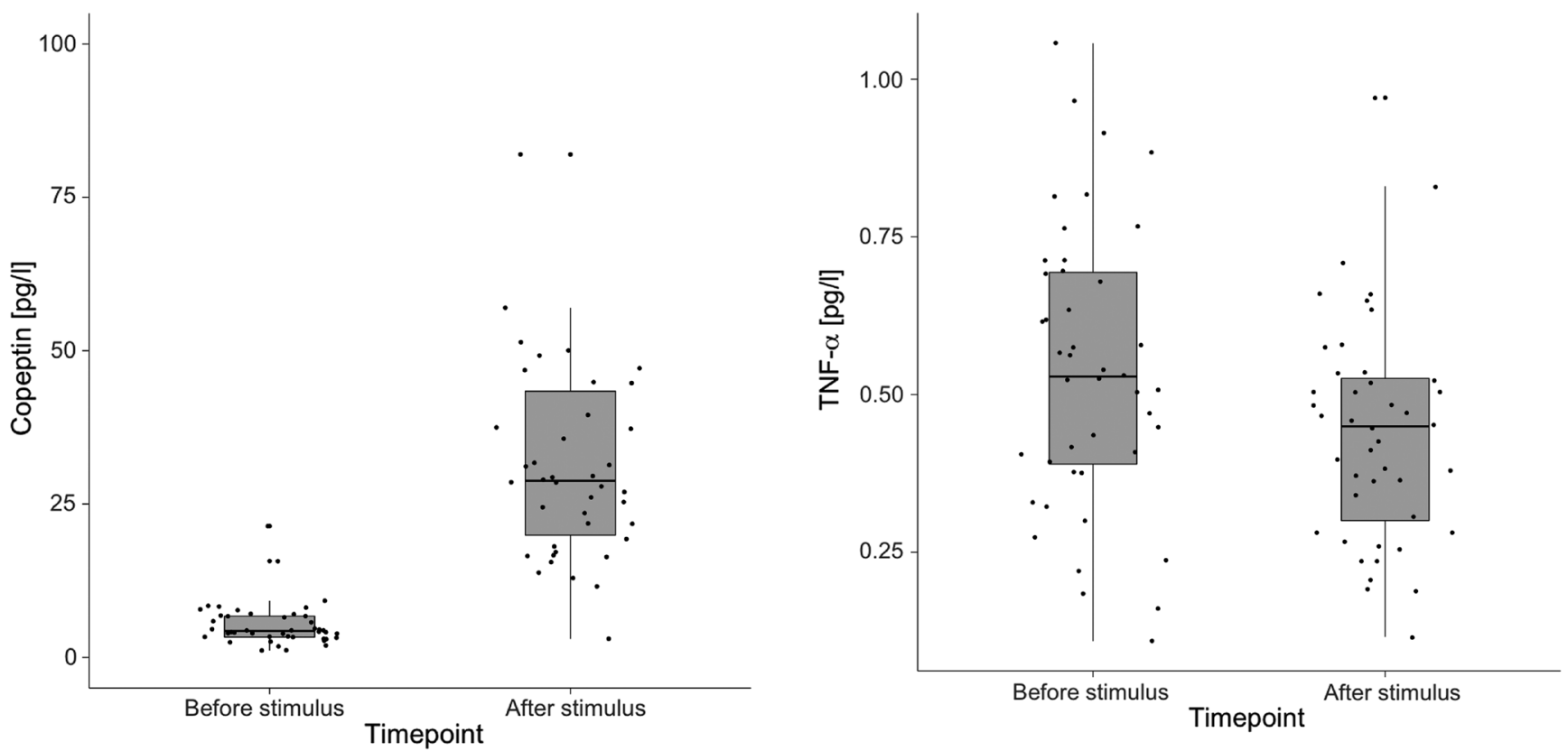

Figure 1

Copeptin before and after osmotic stimulus.

systemic inflammation in healthy volunteers, but instead leads to a decrease in TNF- $\alpha$, a possible decrease in IL- 8 , and unchanged IL-6 levels.

This is in contrast to the literature, where in vitro data suggested an increase in inflammatory parameters upon hyperosmolality $(5,6,7)$. Different explanations for

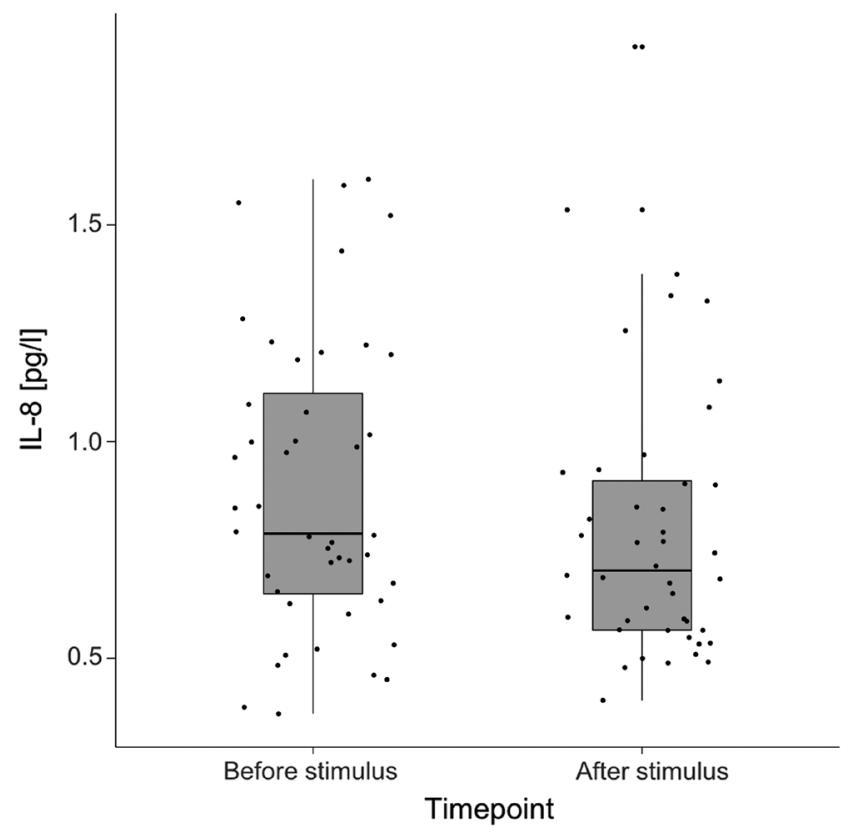

Figure 2

IL-8 before and after osmotic stimulus.

Figure 3

TNF- $\alpha$ before and after osmotic stimulus.

these unexpected findings are possible: first, the hyperosmolar range that is feasible to be induced in animals and in human in vitro cell lines is much higher than the one in healthy humans, reaching up to $1200 \mathrm{mmol} / \mathrm{L}(8,11,12)$. An increase in inflammatory markers was evident at a level of around $400-600 \mathrm{mosmol} / \mathrm{kg}$, whereas we increased serum osmolality only up to $315 \mathrm{mmol} / \mathrm{L}$. This higher osmolality in vitro is likely to be more potent in changing gene expression with subsequent production of inflammatory markers. An increase of serum osmolality to around $315 \mathrm{mosmol} / \mathrm{kg}$ already induced symptoms such as nausea, vomitus and concentration difficulties (15). A higher serum osmolality could induce serious neurological complications and ultimately death (3),

Table 3 Circulating markers of systemic inflammation upon osmotic stimulus.

\begin{tabular}{|c|c|c|c|c|}
\hline \multirow[b]{2}{*}{$\begin{array}{l}\text { Inflammatory } \\
\text { marker }\end{array}$} & \multicolumn{2}{|c|}{$\begin{array}{l}\text { Multiple linear } \\
\text { regression model* }\end{array}$} & \multicolumn{2}{|c|}{ Mixed effect model ${ }^{+}$} \\
\hline & $\begin{array}{l}\text { Effect estimate } \\
\text { of osmotic } \\
\text { stimulus } \\
\end{array}$ & $P$ value & $\begin{array}{l}\text { Effect estimate } \\
\text { of osmotic } \\
\text { stimulus }\end{array}$ & $P$ value \\
\hline IL-8 (pg/L) & -0.08 & 0.3 & -0.08 & 0.17 \\
\hline TNF- $\alpha$ (pg/L) & -0.1 & 0.03 & -0.1 & 0.03 \\
\hline IL-6 (pg/L) & 0.1 & 0.7 & 0.1 & 0.6 \\
\hline
\end{tabular}

*Adjusted for age and sex. ${ }^{+}$With timepoint (before and after stimulus), age and sex as fixed effects and patients as random effect. Bold $P$ values represent statistically significant results.

IL-6, interleukin-6; IL-8, interleukin-8; TNF- $\alpha$, tumor necrosis factor- $\alpha$.

This work is licensed under a Creative Commons Attribution-NonCommercial-NoDerivatives 4.0 Internationab ticense.ifica.com at 04/26/2023 09:56:32AM 
which evidently is not justifiable for a study in healthy humans.

Second, the duration of cell lines and tissue exposed to hyperosmolality was longer in vitro studies than in our population. While the duration of our hyperosmotic stimulus was only for several minutes (as we stopped hypertonic saline infusion once a serum sodium $\geq 150 \mathrm{mmol} / \mathrm{L}$ was reached), cell lines were exposed for several hours to days $(11,13)$. It can therefore be speculated that chronic hyperosmolality is necessary to induce an inflammatory response (16). It is thus possible that a short stimulus into the hypernatremic range might not be sufficient to observe an increase in circulating markers of inflammation.

Third, animal data showed a specific increase in mRNA expression only within the rat central nervous system (supraoptic and paraventricular nuclei of the hypothalamus) (6). However, samples taken from the rat peripheral circulation after hypertonic saline exposure did not indicate an increase in either IL- 6 or IL-1 $\beta$ (17). We cannot conclude from our experiment, whether a central increase in inflammatory markers was present in our population.

Fourth, the medium to induce a hyperosmotic state was either increasing glucose, glucose polyols (D-Mannitol, propylene glycol and glycerol), or serum sodium ( $\mathrm{NaCl}$ (sodium chloride)) $(11,13)$. In our study, we induced hyperosmolality by increasing serum sodium only. In the context of recent advances made regarding the role of glucose-induced inflammation (18), it could be speculated that the rise in inflammatory parameters observed in these studies might be caused by the increase in serum glucose itself rather than the hyperosmolality.

Some of the measured inflammatory markers, that is, TNF- $\alpha$, even decreased upon osmotic stimulus. We can only speculate about possible reasons. It has been shown that inflammatory markers are able to trigger AVP release independent of plasma osmolality $(19,20)$. Possibly, the observed decrease in inflammatory parameters in our study may be because of a negative feedback mechanism of AVP on inflammatory markers.

One study in severely ill patients with SIRS due to ketoacidosis and hyperosmolality showed increased inflammatory markers (14). In these patients, it is however likely that the underlying disease, such as SIRS, triggered the inflammatory response. Furthermore, as mentioned earlier, the increase in glucose levels which commonly occurs in critically ill patients is known to induce inflammation (18).

According to our results, a short increase into the hyperosmotic range, such as in the saline infusion test to differentiate primary polydipsia from diabetes insipidus (15), does not induce an increase in circulating markers of systemic inflammation.

Some limitations of our study need to be mentioned. First, this is a secondary analysis and the results are hypothesis generating and should thus be interpreted with caution. Second, we only increased serum sodium to $150 \mathrm{mmol} / \mathrm{L}$ and serum osmolality to $315 \mathrm{mmol} / \mathrm{L}$ for a short time period, whereas in vitro studies investigated the inflammatory response with higher sodium and osmolality levels and over a longer period of time. However, this is evidently not possible in humans. We can therefore not exclude a rise in inflammatory parameters at a higher osmotic threshold and/or a later rise in inflammatory response after a longer stimulus.

This is the first study investigating circulating markers of systemic inflammation in humans in response to a strong osmotic stimulus into the hypertonic range. It adds valuable inputs on the understanding of hypernatremia and hyperosmolality and inflammation.

In summary, our data show that in healthy volunteers, hyperosmolality by intravenous saline infusion does not increase circulating markers of systemic inflammation which has been shown in animals and in human bronchial, corneal and intestinal cell lines $(8,9$, $10,11,12,13)$. Short-term exposure into a hyperosmotic state such as practiced in a new approach for diabetes insipidus seems not to induce an inflammatory response. Whether this differs for long-term exposure or increased hyperosmolality remains unclear.

\section{Declaration of interest}

W K F and M C C received speaking honoraria by Thermo Fisher Scientific. The other authors have nothing to disclose.

\section{Funding}

This work was supported by Thermo Fisher Scientific Biomarkers (Hennigsdorf, Germany) and by the Margot und Erich Goldschmidt \& Peter René Jacobson-Stiftung (to C O S and to S J W).

\section{Acknowledgments}

The authors thank Cemile Bathelt and Nina Hutter (Clinical Trial Unit, University Hospital Basel) and Mary Beth Gaskill (Clinical Research Unit Laboratory, Northwestern University) for excellent technical assistance.
This work is licensed under a Creative Commons Attribution-NonCommercial-NoDerivatives 4.0 Internationad ticense ifica.com at 04/26/2023 09:56:32AM 


\section{References}

1 Lindner G, Funk GC, Schwarz C, Kneidinger N, Kaider A, Schneeweiss B, Kramer L \& Druml W. Hypernatremia in the critically ill is an independent risk factor for mortality. American Journal of Kidney Diseases 200750 952-957. (https://doi.org/10.1053/j.ajkd.2007.08.016)

2 Nigro N, Winzeler B, Suter-Widmer I, Schuetz P, Arici B, Bally M, Refardt J, Betz M, Gashi G, Urwyler SA, et al. Copeptin levels and commonly used laboratory parameters in hospitalised patients with severe hypernatraemia - the 'Co-MED study'. Critical Care 201822 33. (https://doi.org/10.1186/s13054-018-1955-7)

3 Adrogué HJ \& Madias NE. Hypernatremia. New England Journal of Medicine 2000342 1493-1499. (https://doi.org/10.1056/ NEJM200005183422006)

4 Robertson GL. Abnormalities of thirst regulation. Kidney International 198425 460-469. (https://doi.org/10.1038/ki.1984.39)

5 Bundzikova J, Pirnik Z, Zelena D, Mikkelsen JD \& Kiss A. Response of substances co-expressed in hypothalamic magnocellular neurons to osmotic challenges in normal and Brattleboro rats. Cellular and Molecular Neurobiology 200828 1033-1047. (https://doi.org/10.1007/ s10571-008-9306-x)

6 Ghorbel MT, Sharman G, Leroux M, Barrett T, Donovan DM, Becker KG \& Murphy D. Microarray analysis reveals interleukin-6 as a novel secretory product of the hypothalamo-neurohypophyseal system. Journal of Biological Chemistry 2003278 19280-19285. (https://doi.org/10.1074/jbc.M209902200)

7 Ip WKE \& Medzhitov R. Macrophages monitor tissue osmolarity and induce inflammatory response through NLRP3 and NLRC4 inflammasome activation. Nature Communications 201566931. (https://doi.org/10.1038/ncomms7931)

8 Igarashi T, Fujimoto C, Suzuki H, Ono M, Iijima O, Takahashi H \& Takahashi H. Short-time exposure of hyperosmolarity triggers interleukin-6 expression in corneal epithelial cells. Cornea 201433 1342-1347. (https://doi.org/10.1097/ICO.0000000000000256)

9 Shapiro L \& Dinarello CA. Hyperosmotic stress as a stimulant for proinflammatory cytokine production. Experimental Cell Research 1997231 354-362. (https://doi.org/10.1006/excr.1997.3476)

10 Shapiro L \& Dinarello CA. Osmotic regulation of cytokine synthesis in vitro. PNAS 199592 12230-12234. (https://doi.org/10.1073/ pnas.92.26.12230)

11 Hubert A, Cauliez B, Chedeville A, Husson A \& Lavoinne A. Osmotic stress, a proinflammatory signal in Caco-2 cells. Biochimie 200486 533-541. (https://doi.org/10.1016/j.biochi.2004.07.009)
12 Németh ZH, Deitch EA, Szabó C \& Haskó G. Hyperosmotic stress induces nuclear factor-kappaB activation and interleukin-8 production in human intestinal epithelial cells. American Journal of Pathology 2002161 987-996. (https://doi.org/10.1016/s00029440(10)64259-9)

13 Hashimoto S, Matsumoto K, Gon Y, Nakayama T, Takeshita I \& Horie T. Hyperosmolarity-induced interleukin-8 expression in human bronchial epithelial cells through p38 mitogen-activated protein kinase. American Journal of Respiratory and Critical Care Medicine 1999159 634-640. (https://doi.org/10.1164/ ajrccm.159.2.9712090)

14 Gogos CA, Giali S, Paliogianni F, Dimitracopoulos G, Bassaris HP \& Vagenakis AG. Interleukin-6 and C-reactive protein as early markers of sepsis in patients with diabetic ketoacidosis or hyperosmosis. Diabetologia 200144 1011-1014. (https://doi.org/10.1007/ s001250100592)

15 Fenske WK, Schnyder I, Koch G, Walti C, Pfister M, Kopp P, Fassnacht M, Strauss K \& Christ-Crain M. Release and decay kinetics of copeptin vs AVP in response to osmotic alterations in healthy volunteers. Journal of Clinical Endocrinology and Metabolism 2018103 505-513. (https://doi.org/10.1210/jc.2017-01891)

16 Schwartz L, Guais A, Pooya M \& Abolhassani M. Is inflammation a consequence of extracellular hyperosmolarity? Journal of Inflammation 20096 21. (https://doi.org/10.1186/1476-9255-6-21)

17 Santos-Junior NN, Costa LHA, Catalão CHR, Kanashiro A, Sharshar T \& Rocha MJA. Impairment of osmotic challenge-induced neurohypophyseal hormones secretion in sepsis survivor rats. Pituitary 201720 515-521. (https://doi.org/10.1007/s11102-0170812-z)

18 Dror E, Dalmas E, Meier DT, Wueest S, Thévenet J, Thienel C, Timper K, Nordmann TM, Traub S, Schulze F, et al. Postprandial macrophage-derived IL-1 $\beta$ stimulates insulin, and both synergistically promote glucose disposal and inflammation. Nature Immunology 201718 283-292. (https://doi.org/10.1038/ni.3659)

19 Palin K, Moreau ML, Sauvant J, Orcel H, Nadjar A, DuvoidGuillou A, Dudit J, Rabié A \& Moos F. Interleukin-6 activates arginine vasopressin neurons in the supraoptic nucleus during immune challenge in rats. American Journal of Physiology. Endocrinology and Metabolism 2009296 E1289-E1299. (https://doi.org/10.1152/ ajpendo.90489.2008)

20 Swart RM, Hoorn EJ, Betjes MG \& Zietse R. Hyponatremia and inflammation: the emerging role of interleukin- 6 in osmoregulation. Nephron Physiology 2011118 45-51. (https://doi. org/10.1159/000322238)

Received in final form 6 August 2019

Accepted 19 August 2019

Accepted Preprint published online 20 August 2019 https://ec.bioscientifica.com https://doi.org/10.1530/EC-19-0280 (c) 2019 The authors Published by Bioscientifica Ltd
This work is licensed under a Creative Commons Attribution-NonCommercial-NoDerivatives 4.0 delaternationab ticense.ifica . com at 04/26/2023 09:56:32Am 